\title{
LA PERSPECTIVA DE LOS ESTADOS DEL MAGREB EN CUANTO A LA IMPORTACIÓN Y LA EXPORTACIÓN DE PRODUCTOS ALIMENTICIOS
}

\author{
Beatriz Tomé ${ }^{1}$ \\ Universidad Complutense de Madrid (UCM) / UNISCI
}

\begin{abstract}
Resumen:
Este artículo pretende completar el análisis ofrecido por otros autores en este mismo número UNISCI al partir desde la perspectiva de los países del Magreb central sobre el intercambio de productos agroalimentarios con la Unión Europea. Sostiene que estas relaciones comerciales particulares forman parte fundamental de la extensa y plural red de lazos euro-magrebíes e influyen de forma decisiva no sólo en la política exterior de Marruecos, Túnez y Argelia, sino también en cuestiones internas. El comercio agro-alimentario ha de entenderse pues desde una doble dialéctica de influencias mutuas y constantes entre el plano internacional (nivel de análisis I) y el plano doméstico (nivel de análisis II). El trabajo sostiene que los Acuerdos entre la UE y los denominados Países Terceros Mediterráneos (PTM) no reflejan únicamente las expectativas 'del norte', sino también los intereses y agendas de los Estados magrebíes.
\end{abstract}

Palabras clave: Comercio de Alimentos, Magreb, Unión Europea, Marruecos, Argelia, Túnez, Agricultura.

Title in English: "Perspectives from Maghreb States Regarding Import and Export of Food Products"

\begin{abstract}
:
This article tries to complement the views offered by other authors in this volume with the proviso that my point of departure stands on the Maghreb perspective regarding the agricultural trade with the European Union (EU). I argue that these particular trade relations constitute a key element in the extensive and plural Euro-Maghreb network and that they influence not only the external relations of Morocco, Tunisia and Algeria, but also their internal ones. The agro-trade reflects the mutual and contant influences among the international level (level of analysis I) and the domestic one (level os analysis II). In this paper I seek to explore how the agreements between the EU and the Mediterranean Thrid Countries (MTC) do reflect not only European expectations, but also the interests and agendas of the Maghreb States.
\end{abstract}

Keywords: Food trade, Maghreb, EU, Morocco, Algeria, Tunisia, Agriculture.

Copyright (C) UNISCI, 2013.

Las opiniones expresadas en estos artículos son propias de sus autores, y no reflejan necesariamente la opinión de UNISCI. The views expressed in these articles are those of the authors, and do not necessarily reflect the views of UNISCI.

\footnotetext{
${ }^{1}$ Beatriz Tomé Alonso es becaria FPU del Ministerio de Educación, investigadora de UNISCI, y miembro del Foro Hispano-Argelino.

Dirección: Departamento de Estudios Internacionales, Facultad de Ciencias Políticas y Sociología, UCM,

Campus de Somosaguas, 28223 Madrid, España.

E-mail: beatriz.tome@hotmail.com.

http://dx.doi.org/10.5209/rev_UNIS.2013.n31.44700
} 


\section{Introducción}

En febrero de 2012 Marruecos y la Unión Europea firman el Acuerdo para la liberación del comercio de productos agrícolas y de productos de pesca, lo que supone un avance en el proceso de "integración progresiva" de ambos mercados. Marruecos es uno de los cuatro países del sur del Mediterráneo con los que la Unión Europea pretende alcanzar un acuerdo de libre comercio profundo y completo que incluya, desde el inicio de las negociaciones, los productos agrícolas ${ }^{2}$. Si bien la Zona de Libre Comercio (ZLC) euro-mediterránea estaba prevista desde el Acuerdo de Barcelona (1995), este renovado impulso ha de entenderse en el contexto de las repercusiones y consecuencias de la Primavera Árabe y de la voluntad de la Unión Europea de responder a los nuevos desafíos que se le presentan "haciendo uso de [sus] instrumentos comerciales y económicos"3. La UE considera que "la apertura de los mercados y la integración progresiva en [su] mercado interior (..) pueden ser instrumentos poderosos para el desarrollo de los países del sur del Mediterráneo y ayudar a mitigar la pobreza generalizada y el desempleo que provoca problemas económicos, migratorios y de seguridad en la región""

Los países del Magreb central -Marruecos, Túnez y Argelia- han recibido, a excepción quizás del último, esta nueva impronta en el comercio de productos agro-alimentarios con optimismo. No en vano y a pesar de la entrada de terceros actores, como China o los Estados del Golfo, la UE sigue siendo su primer socio comercial. También en lo relativo al comercio de productos agrícolas (y ganaderos), que persiste como uno de los elementos más problemáticos en las relaciones bilaterales y que es, muy a menudo, presa de otros intereses.

La pauta de liberalización e integración progresiva que dibuja en el horizonte un mercado común ha resultado lenta y problemática. De un lado, debido al proteccionismo de la Unión y la presión de grupos de poder para limitar la entrada de productos agrícolas magrebíes. Existe la creencia, especialmente en la Europa del sur, que este libre acceso supondrá un grave riesgo para la supervivencia del agricultor local y de los estándares sanitarios y fitosanitarios europeos ${ }^{5}$. Del otro lado, la transición magrebí "desde un desarrollo nacionalista hacia el énfasis sobre la acumulación de capital privado bajo un régimen de liberalismo económico e internacionalismo" 6 no puede entenderse como un camino unidireccional abocado a un área de intercambio en el que no haya barreras. Persisten las dinámicas y lógicas propias de un fuerte control estatal sobre un sector estratégico ligado al mantenimiento de la paz social y a la inserción de las economías magrebíes en el mercado internacional.

\footnotetext{
${ }^{2}$ El Consejo de la Unión ha aprobado directrices de negociación para un Acuerdo de Libre Comercio Profundo y Completo -en inglés Deep and Comprehensive Free Trade Areas (DCFTA)- con cuatro países del sur del Mediterráneo: Marruecos, Egipto, Jordania y Túnez: ver "The EU's response to the 'Arab Spring'", en http://europa.eu/rapid/press-release_MEMO-11-918_en.htm.

"Resolución del Parlamento Europeo sobre el Acuerdo UE-Marruecos sobre medidas recíprocas de liberalización del comercio de productos agrícolas y productos de la pesca", 16 de febrero de 2012, en http://www.europarl.europa.eu/sides/getDoc.do?pubRef=-//EP//TEXT+TA+P7-TA-2012$0055+0+\mathrm{DOC}+\mathrm{XML}+\mathrm{V} 0 / / \mathrm{ES}$.

${ }^{4}$ Ibid.

${ }^{5}$ Ver, a modo de ejemplo: “A 'tomatazo limpio' contra el acuerdo agrícola con Marruecos”, El Mundo, 14 de febrero de 2012; “Accord Agricole Maroc-UE. Bové: 'Nous ferons tout pour faire barrage'”, L'Economiste, 27 de enero de 2012.

${ }^{6}$ Walton, John and Seddon, David (1994): Free Markets and Food Riots. The Politics of Global Adjustment, Oxford UK and Cambridge USA, Blackwell.
} 
Este artículo pretende completar el análisis ofrecido por otros autores en este mismo número al ofrecer la perspectiva de los países del Magreb central sobre el intercambio de productos agro-alimentarios con la Unión Europea. Sostiene que estas relaciones comerciales particulares forman parte fundamental de la extensa y plural red de lazos euro-magrebíes e influyen de forma decisiva no sólo en la política exterior de Marruecos, Túnez y Argelia, sino también en cuestiones internas. El comercio agro-alimentario ha de entenderse pues desde una doble dialéctica de influencias mutuas y constantes entre el plano doméstico y el plano internacional y entre los países del Magreb central y la Unión Europea. Para entender la comunicación entre estos dos niveles resulta particularmente útil el modelo de análisis expuesto por Putnam, que relaciona los acuerdos internacionales (nivel I) y los procesos de ratificación interna (nivel II).

\section{El sector agro-alimentario: sector estratégico para el Magreb central}

Son varios los condicionantes que convierten al sector agro-alimentario en un sector estratégico: la importancia del campo -en términos de PIB y de empleo de población- en las economías en desarrollo; los nexos entre construcción nacional y poder rural establecidos desde la época de las independencias; la íntima relación entre seguridad alimentaria y paz social; y particularismo geográfico y geopolítico (la proximidad con el mercado europeo y los intereses particulares europeos sobre la zona).

Una de las características principales de las economías en desarrollo es el alto porcentaje de la mano de obra dedicado a la agricultura y a las actividades del sector informal $^{7}$. La primera se convierte, por tanto, en un sector económica y socio-políticamente estratégico. Representa en torno al 20\% del Producto Interior Bruto (PIB) de Marruecos, el $10,6 \%$ del de Túnez y el $12 \%$ del PIB argelino ${ }^{8}$. Ha servido de manera recurrente "como empleo de último recurso (...), un importante sector 'buffer' que ha ayudado a absorber los efectos de los shocks externos.". 9

La buena marcha del sector asegura una cierta paz social y la continuación de las políticas de desarrollo. Varios autores han establecido un nexo claro entre la subida de precios de bienes básicos de consumo y las revueltas populares. ${ }^{10}$ La seguridad alimentaria se torna, por tanto, 'núcleo duro' de las políticas de los países del Magreb central. El crecimiento demográfico, la subida de los precios de los alimentos en el mercado mundial y el previsible impacto del cambio climático sobre la región ha aumentado la preocupación de los gobiernos de los Estados magrebíes, cuyos índices de desnutrición están, según el último informe de la

\footnotetext{
${ }^{7}$ Devlin, Julia C. (2010): Challenges of Economic Development in the Middle East and North Africa Region, Singapore, World Scientific Publishing Co. Pte. Ltd., p.18.

${ }^{8}$ Los porcentajes del sector agrícola respecto al PIB varían ligeramente de unas fuentes a otras. Tomamos como referencia los datos de CIA (2012): The World Factbook, en https://www.cia.gov/library/publications/the-worldfactbook/.

${ }^{9}$ Devlin, op.cit., p. 18 .

${ }^{10}$ Según Walton y Seddon "en prácticamente todos los casos, subidas significativas del coste de los productos y servicios básicos (o la amenaza de subida) han precedido y precipitado de forma efectiva el estallido de la protesta popular. El precio del pan y otros alimentos básicos parece ser particularmente significativo, en parte debido a su importancia sobre el gasto doméstico, especialmente para la clase urbana menos favorecida, pero también en parte debido a su valor simbólico (particularmente aplicable al caso del pan): en Walton and Seddon, op.cit.
} 
FAO, en torno al 5\% ${ }^{11}$. El hecho de que la 'llama' de Primavera Árabe comenzara en una zona rural $^{12}$ y constituya un claro ejemplo de (a) las dificultades de buena parte de la población magrebí de acceso a bienes de primera necesidad y (b) las diferencias entre el mundo rural y urbano de sociedades que se desarrollan a dos velocidades ha subrayado aún más lo estratégico del sector agrícola.

Buena parte, por tanto, de las políticas de los tres países magrebíes han ido destinadas a asegurar el abastecimiento de sus mercados. "Las medidas políticas han ampliamente intentado mejorar la seguridad de suministro en parte mediante inversiones en infraestructuras hidráulicas de larga escala más que en asociaciones basadas en los usuarios, mientras han tendido a beneficiar a los grandes agricultores en áreas de irrigación y productores de bienes estratégicos capaces de ganar cuota en el mercado extranjero." ${ }^{13}$ Como consecuencia, tanto en Túnez como en Marruecos se ha beneficiado un desarrollo dual y en paralelo de la agricultura, donde conviven formas de planificación estatal con aperturas limitadas. Responde a un triple objetivo: (a) emplear a mano de obra con escasa formación; (b) beneficiar y proteger a una élite rural tradicionalmente asociada con el poder central; y (c) responder a presiones comunes de la UE para liberalizar una parte de la agricultura y de una parte de la élite magrebí que busca beneficiarse de la proximidad del mercado europeo y que resultarán ganadores en el proceso. La denominada agricultura de subsistencia, que cuenta con escasos y rudimentarios medios, convive con las explotaciones dedicadas al desarrollo del potencial exportador. En el plano doméstico, "una combinación de controles de precios agrícolas, subsidios y protección tarifaria ha contribuido a multiplicar los niveles de intervención de precios, conduciendo a una ruptura entre precios domésticos e internacionales, precios de consumo y de producción [lo que] ha servido igualmente para seleccionar los intereses urbanos y de la élite rural."14

Junto a estas políticas de orden doméstico, se han desarrollado relaciones comerciales exteriores destinadas a abastecer el mercado nacional. Tanto Túnez como Argelia tienen un déficit comercial importante en el ámbito de los productos agro-alimentarios respecto a la Unión Europea. Marruecos es la única excepción. El sector agro-alimentario es además una pieza clave en el proceso de inserción en el mercado internacional de la región, especialmente en lo que concierne a sus relaciones con la UE. Si bien la región MENA (Middle East and North Africa countries) nunca ha estado apartada del proceso de globalización, lo cierto es que su pertenencia siempre ha estado sujeta a condiciones particulares. Se basa esencialmente en tres o cuatro sectores para generar y mantener su potencial exportador y se caracteriza por tener un número limitado de socios comerciales. La mayoría de los productos son volátiles en precio -como el petróleo, el gas natural, los fosfatos o la agricultura-, lo que crea diversos retos, como la gestión de las tasas de intercambio y el diseño de una política fiscal adecuada. ${ }^{15}$

\footnotetext{
${ }^{11}$ Para el periodo 2010-1012, el índice de desnutrición, en porcentaje de la población, es del 5,5\% en Marruecos y el $5 \%$ en Túnez y Argelia. La media del mundo es de 12,9\%, mientras que la de las regiones desarrolladas es el 1,3\% y el de las regiones en desarrollo el 15,5\%. Mientras Argelia y Túnez conservan el mismo índice de desnutrición que para el periodo 2007-1009, la situación de Marruecos ha empeorado ligeramente. Para el periodo 2007-2009, el índice de desnutrición era 5,2\%.Ver: Food and Agriculture Organization of the United Nations (FAO) (2012): The State of Food Insecurity in the World 2012, Rome, en http://www.fao.org/publications/en/.

${ }^{12}$ Mohamed Elloumi interpreta la Revolución tunecina del 14 de enero como "una crisis del mundo rural y de los modelos de desarrollo": en la Mesa Redonda "Nouvelle Democratie, Nouvelles Cooperations. Le cas de la Tunisie", 17èmes Controverses européennes de Marciac: La future PAC à l'épreuve des grands bouleversements du Monde, 3 et 4 agosto 2011.

${ }^{13}$ Devlin, op.cit., p.189.

${ }^{14}$ Idem.

${ }^{15}$ Idem.
} 


\section{Hipótesis y marco teórico}

Este artículo sostiene que el comercio de productos agro-alimentarios ocupa un lugar clave en las relaciones entre la UE y los países del Magreb e influye de forma decisiva en la planificación agrícola y agro-industrial de los últimos, que buscan no sólo el desarrollo en términos de autarquía (tendencia al auto-abastecimiento), sino también la creación de un nicho de exportación. Por tanto, los acuerdos agrícolas euro-magrebíes responden:

- A la voluntad de los Estados magrebíes de inserción en la economía global y posicionamiento en la escena internacional mediante un sector en el que mantienen cierta ventaja competitiva debido a la combinación de mano de obra barata y grandes áreas de cultivo.

- Al objetivo de desarrollar un sector que produce un alto porcentaje del PIN, que emplea a buena parte de la población activa y que está relacionado de forma directa con la distribución del poder en el ámbito nacional.

- A la asunción por parte de los denominados 'terceros países' del rol asignado desde la UE: se convierten en productores especializados en bienes demandados desde el mercado europeo siguiendo la lógica de la distribución de la producción.

Entre las agendas de las partes concernidas se produce un proceso de mutua influencia y dialéctica constante. En tanto (a) primer socio comercial, y/o (b) mayor suministrador de alimentos y/o (c) parte fundamental en la estrategia de inserción en el mercado internacional de las economías magrebíes, la Unión Europea influye en los procesos domésticos del Magreb. Esta influencia actúa en los dos sentidos. Marruecos, Túnez y Argelia también tienen una agenda propia que tratan de hacer valer ante las instituciones europeas.

La ausencia de homogeneidad entre los países del Magreb central exige, sin embargo, cierta cautela en el establecimiento de hipótesis comunes. Si bien los casos de Marruecos y Túnez guardan mayores similitudes, Argelia requiere una mención específica. Sus reservas de gas -y los ingresos que generan- se convierten en principio rector del desarrollo nacional y de las relaciones exteriores. Los hidrocarburos modifican la pauta de relación de la región con la Unión Europea -al absorber casi la totalidad del volumen de exportaciones- y permiten al Estado maniobrar con la subida de subsidios para frenar las protestas populares.

Este artículo ofrece la perspectiva de los países del Magreb central en este proceso de doble dialéctica entre el plano doméstico y el plano internacional y entre la UE, de un lado, y Marruecos, Túnez y Argelia, de manera bilateral, del otro. Desde una aproximación "insideout" magrebíes en materia agro-alimentaria y su proyección sobre los acuerdos de intercambios comerciales con la UE. Frente a otras visiones que priorizan la influencia de "fuera-haciadentro", nuestra hipótesis sostiene que dichos acuerdos y dichos intercambios no reflejan únicamente las expectativas 'del norte', sino que reflejan las percepciones y las motivaciones de los denominados 'terceros Estados'.

\footnotetext{
${ }^{16}$ La aproximación "inside-out" puede encontrarse en los trabajos de Frédéric Vilpí, así como de otros autores tales como Michelle Pace o Francesco Cavatorta. Ver, entre otros, M. Pace; P. Seeberg y F. Cavatorta: "The EU's democratization agenda in the Mediterranean: a critical inside-out approach", Democratization, vol. 16, $\mathrm{n}^{\mathrm{o}}$.1, (Febrero 2009).
} 
Tomamos como punto de partida teórico el modelo de juego en dos niveles desarrollado por Putnam, que vincula las negociaciones de los acuerdos internacionales (nivel I) -entre los que se incluirían los acuerdos de intercambio de productos agrícolas- con la necesidad de obtener ratificación de dicho acuerdo a nivel doméstico (nivel II) ${ }^{17}$. Se hacen necesarios, sin embargo, algunos cambios sobre el modelo inicial. Tal y como indica Dawson, el juego a dos niveles de Putnam fue desarrollado en el contexto de Estados industriales avanzados gobernados por democracias representativas, por lo que su aplicación a Marruecos (y al resto de países del Magreb central) proveerá percepciones útiles sobre cómo funcionan la defensa de los intereses y la necesidad de ratificación del acuerdo a otros niveles más allá del referido a la opinión pública y podría arrojar luz sobre la manera en que los intereses políticos domésticos conforman los tratados internacionales. ${ }^{18}$

El modelo propuesto, que establece dos niveles de análisis (plano internacional y plano doméstico), nos permite combinar una perspectiva teórica y otra de carácter más empírico. De una parte, expone los términos en los que se realiza el intercambio bilateral de productos agro-alimentarios entre los países del Magreb y la UE; de otro, relaciona los acuerdos alcanzados con condicionantes, intereses y desarrollos concretos en el escenario doméstico magrebí.

\section{Cuadro 1, Modelo de análisis (basado en modelo de juego en dos niveles desarrollado por Putnam)}

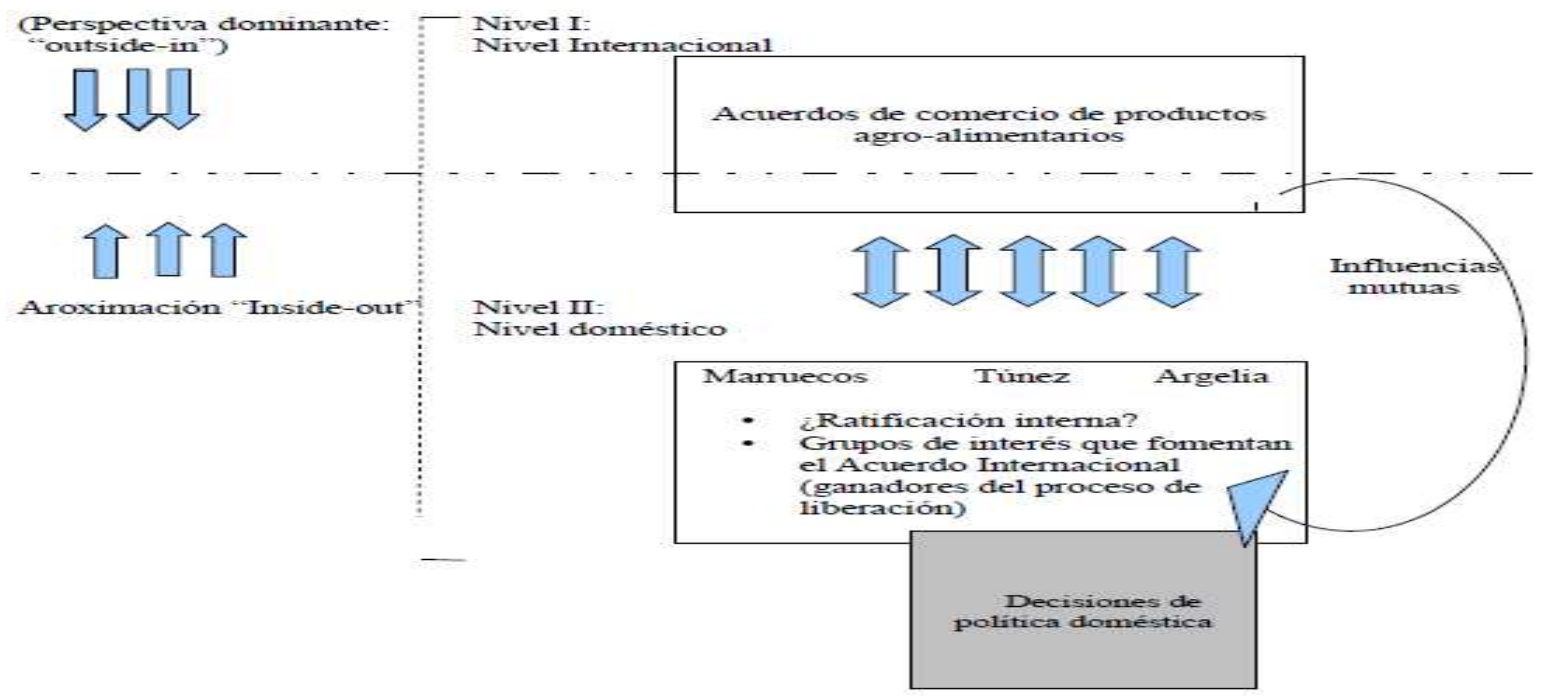

Fuente: Elaboración propia

\footnotetext{
17 Putnam, Robert D: "Diplomacy and domestic politics: the logic of two-level games", International Organization, vol. 42, $\mathrm{n}^{\circ}$ 3, (Junio 1988).

${ }^{18}$ Dawson, Carl (2009): EU Integration with North Africa. Trade Negociations and Democracy. Deficits in Morocco, London-New York, Tauris Academic Studies.
} 


\section{El no-Magreb o la persistencia de los particularismos. El necesario análisis individualizado}

El Magreb central constituye para la Unión Europea una unidad geopolítica relativamente cohesionada debido a su posición estratégica en términos de seguridad, economía y política. Clave en el abastecimiento energético de Europa del sur y destinataria de generosas partidas presupuestarias, la región es percibida como origen de oleadas de inmigrantes, punto caliente del tráfico de drogas y matriz de movimientos terroristas.

A pesar de esta naturaleza común pretendida, el Magreb central no conforma una realidad unificada ni uniforme. Algunas voces incluso se refieren al área como el no-Magreb (y su coste $)^{19}$. La ausencia de integración sur-sur, marcada por las malas relaciones entre Argelia y Marruecos, provoca que se persigan intereses particulares y hasta en términos de competencia por la obtención de cuotas de mercado y acuerdos preferentes. A la falta de unidad -señalada por el Fondo Monetario Internacional (FMI) como un desventaja para los propios Estados magrebíes, que han de afrontar sus problemas de manera individual y aislada en vez de formando un frente común $^{20}$, hay que añadir la falta de uniformidad. Cada País Tercero Mediterráneo (PTM) tiene una realidad política y económica particular y un peso específico del sector agrícola dentro de ella y respecto al enjambre relacional europeo. Si bien encontramos numerosas similitudes entre Marruecos y Túnez, Argelia se desmarca por la vía de los hidrocarburos. Se impone, por tanto, el análisis diferenciado de cada escenario nacional y de su perspectiva particular respecto a las relaciones comerciales en materia de alimentos con la UE. Un esquema de trabajo propiciado desde la propia Unión, que parece haber relegado el marco multilateral iniciado en Barcelona (1995) a favor de unas negociaciones individuales y particularizadas.

\subsection{La perspectiva marroquí}

\subsubsection{La agricultura: un sector económico y políticamente relevante}

En la estructura económica marroquí, el sector agrícola representa el 20\% del PIB (el 16\% corresponde a la agricultura y el $4 \%$ a la agro-industria) ${ }^{21}$. Esta cifra no refleja, sin embargo, lo estratégico del sector para el país, que emplea, según datos del Banco Mundial, al $41 \%$ de la población marroquí. El porcentaje se eleva hasta el $75 \%$ si nos referimos de forma

\footnotetext{
${ }^{19}$ Ver Larabi Jaïdi: "The cost of "non-Maghreb" is too high a price to pay”, Europe's World, (Primavera 2012), en

http://www.europesworld.org/NewEnglish/Home_old/Article/tabid/191/ArticleType/ArticleView/ArticleID/218 07/language/en-US/Default.aspx.

${ }^{20}$ Ver: "Le FMI critique l'insuffisance des échanges au Maghreb", Le Figaro, 8 de enero de 2013; Ghiles, Francis: “Le «non-Maghreb» coûte cher au Maghreb”, Le Monde Diplomatique, (Enero 2010).

${ }^{21}$ Según CIA (2012): World Factbook: Morocco, el $16.6 \%$ por del PIB procede de la agricultura, la industria representa el $32.2 \%$ y los servicios el $51.2 \%$, en https://www.cia.gov/library/publications/the-world-factbook/. Ver Mesa, Beatriz: "Marruecos ve el acuerdo agrícola con la UE como un paso importante hacia la integración", ARN Digital, 20 de febrero de 2012.

${ }^{22}$ Ver Banco Mundial: "Empleos en agricultura (\% del total de empleos)", en

http://datos.bancomundial.org/indicador/SL.AGR.EMPL.ZS. Según la fuente consultada, la cifra exacta puede variar ligeramente. En un informe reciente de la Unión Europea se afirma que la agricultura "supone (..) el 38\% de la mano de obra marroquí, con picos que llegan entorno al 75\% en las zonas rurales, que esto demuestra que la estabilidad y la expansión de este sector es tremendamente importante para la estabilidad política del país.", ver Parlamento Europeo: "Resolución del Parlamento Europeo sobre el Acuerdo UE-Marruecos sobre medidas recíprocas de liberalización del comercio de productos agrícolas y productos de la pesca", 16 de febrero de 2012, en
} 
exclusiva al entorno rural, que tradicionalmente ha supuesto una importante fuente de apoyo al trono frente los focos de oposición concentrados en las ciudades ${ }^{23}$.

\section{Gráfico 1. Estructura de empleo según el Sector de Actividad Económicamente}

(a) sobre la totalidad del país

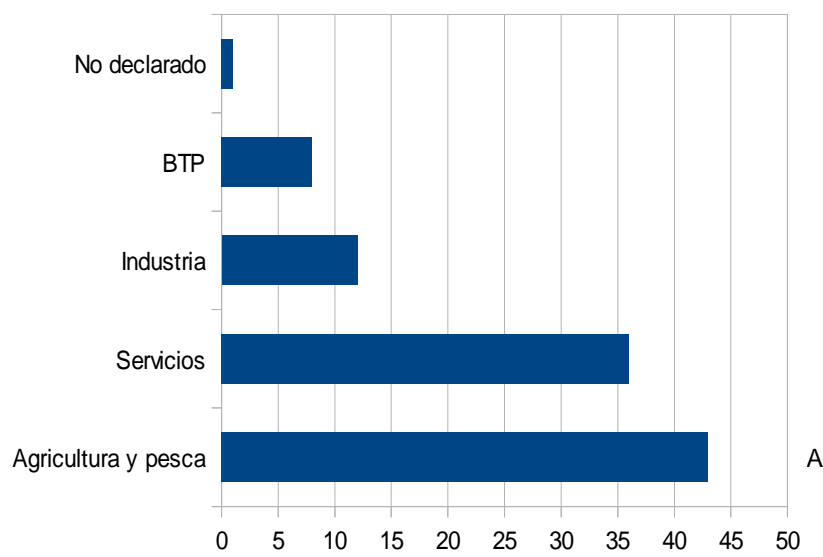

(b) en las zonas rurales (empleo rural)

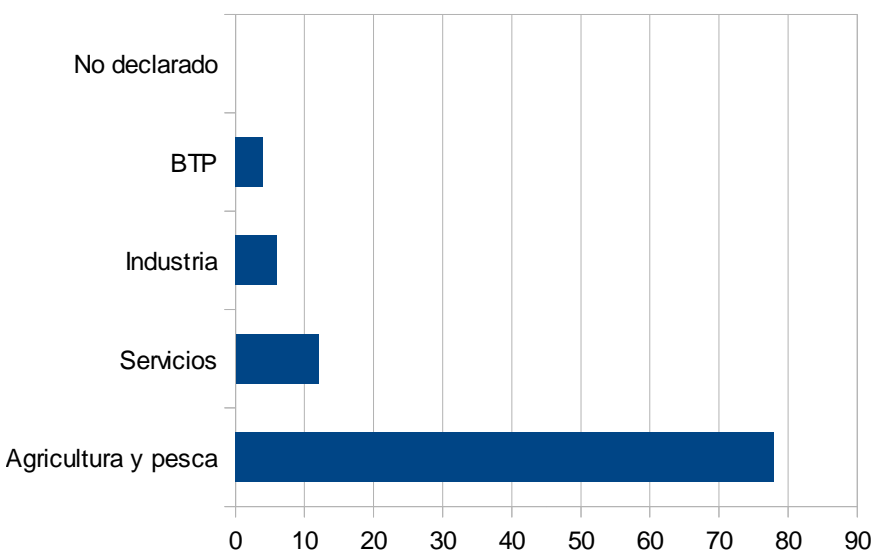

Fuente: Ministerio de Agricultura de Marruecos: La agricultura en cifras

La agricultura, principio rector de la economía marroquí, se ha beneficiado durante las últimas décadas de las estrategias de desarrollo gubernamentales. Un desarrollo, no obstante, de naturaleza dual. Junto a la agricultura "de subsistencia", definida por un alto impacto de las condiciones climatológicas no siempre favorables y por la falta de modernización técnica y de profesionalización, crece una industria orientada a la exportación. El Plan Verde, inaugurado en 2008, trabaja en estas dos direcciones complementarias y paralelas ${ }^{24}$ :

1 Pilar I: desarrollo que una agricultura moderna altamente productiva y de fuerte valor añadido con la que extender los nexos (comerciales y de inversión) con el exterior. La inversión es privada, pero podrá contar con el acompañamiento del Estado, que a través del Fondo de Desarrollo Agrícola (FDA), proporcionará un apoyo específico a los proyectos de agregación -que permitirá la creación de cooperativas de agricultores en torno a una figura física o moral-.

2 Pilar II: protección lo que denomina "agricultura de solidaridad". El objetivo es aumentar la producción de las áreas desfavorecidas mediante proyectos agrícolas económicamente viables y respetuosos con el medio ambiente. La intervención del Estado será directa en ciertas zonas marginales.

http://www.europarl.europa.eu/sides/getDoc.do?pubRef=-//EP//TEXT+TA+P7-TA-2012$0055+0+\mathrm{DOC}+\mathrm{XML}+\mathrm{V} 0 / / \mathrm{ES}$.

${ }^{23}$ El campesino (fellah) ha sido señalado por numerosos autores como fuente de apoyo del poder estabecido, ya desde la época de la colonización: ver Leveau, Rémy (1985): Le fella marocain défenseur du trône, Paris, Presses de Sciences Po (primera edición de 1976). Sobre el apoyo del campo al reinado de Hassan II ver Desrues, Thierry: "Le corporatisme agrarien au Maroc. La trajectoire de l'Union marocaine de l'agriculture", Revue des Mondes Musulmans et de la Méditerranée (REMMM), nº 111-112, pp. 197-217.

${ }^{24}$ Agence pour le Developpement Agricole: "Plan Maroc Vert", en http://www.ada.gov.ma/Plan_Maroc_Vert/plan-maroc-vert.php. 


\subsubsection{El comercio con la Unión Europea en materia de alimentos}

La exportación de productos agro-alimentarios -entre los que se incluye la pesca, que representa el $55 \%$ de las exportaciones y mantiene unos 400.00 empleos $^{25}$ - es una cuestión política y económica capital en las relaciones Marruecos - UE. El mercado común europeo se mantiene como el principal mercado exterior y como gancho en la internacionalización de los productos marroquíes. Del él provienen el $50 \%$ de las importaciones y a él se dirigen el $59 \%$ de las exportaciones totales ${ }^{26}$.

Tabla 1. Repartición de los intercambios comerciales por región (según datos de 2010)

$\begin{array}{lcr}\text { Continentes/\% } & \text { Importaciones } & \text { Exportaciones } \\ \text { Europa } & 57,6 & 65,3 \\ \text { América } & 11,7 & 8,9 \\ \text { África } & 5,9 & 9,8 \\ \text { Asia } & 24,5 & 15,1 \\ \text { Oceanía } & 0,3 & 0,9 \\ \text { TOTAL } & 100 & 100\end{array}$

Tabla 2. Evolución de las exportaciones marroquíes

$\begin{array}{lcc}\text { Valeur en Millions EURO } & 2009 & 2010 \\ \text { Alimentación, bebidas, tabaco } & 2255,43 & 2209,24 \\ \text { Energía y lubricantes } & 235,29 & 388,47 \\ \text { Productos en bruto } & 873,67 & 1605,43 \\ \text { Semi-productos } & 2324,3 & 3821,71 \\ \text { Productos acabados de equipamiento } & 1461,61 & 1985 \\ & & \\ \text { Productos de consumo } & 2967,87 & 3226,48 \\ \text { TOTAL } & 10118,17 & 13236,33\end{array}$

Fuente: Maroc Export, en http://www.marocexport.ma

\footnotetext{
${ }^{25}$ Ver Organización de las Naciones Unidas para la Alimentación y la Agricultura (FAO): "Marruecos-Perfiles por países del Recurso Pastura/Forrajee" (2005), en

http://www.fao.org/ag/AGP/AGPC/doc/Counprof/spanishtrad/Morocco_sp/Morocco_sp.htm.

26 "EU-Moroccan Agreement on Agricultural and Fishery Products", Library of the European Parliament, 10 de febrero de 2012.
} 
Los productos de agricultura y pesca representan el 18\% de las exportaciones totales marroquíes ${ }^{27}$ y sitúan al país en una posición ventajosa respecto a sus vecinos. Marruecos se aleja de la pauta marcada por el resto de Países Socios Mediterráneos (PSM), con los que la UE tiene un importante superávit comercial de más de 4000 millones de euros en el ámbito de la agricultura y la pesca. Con Marruecos, sin embargo, el déficit comercial bilateral alcanzó en 2010 la cifra de 871 millones de euros en relación a los intercambios bilaterales de agricultura, pesca y alimentos ${ }^{28}$.

\section{Gráfico 2. Evolución del comercio de agricultura y pesca entre la UE y Marruecos (€m)}

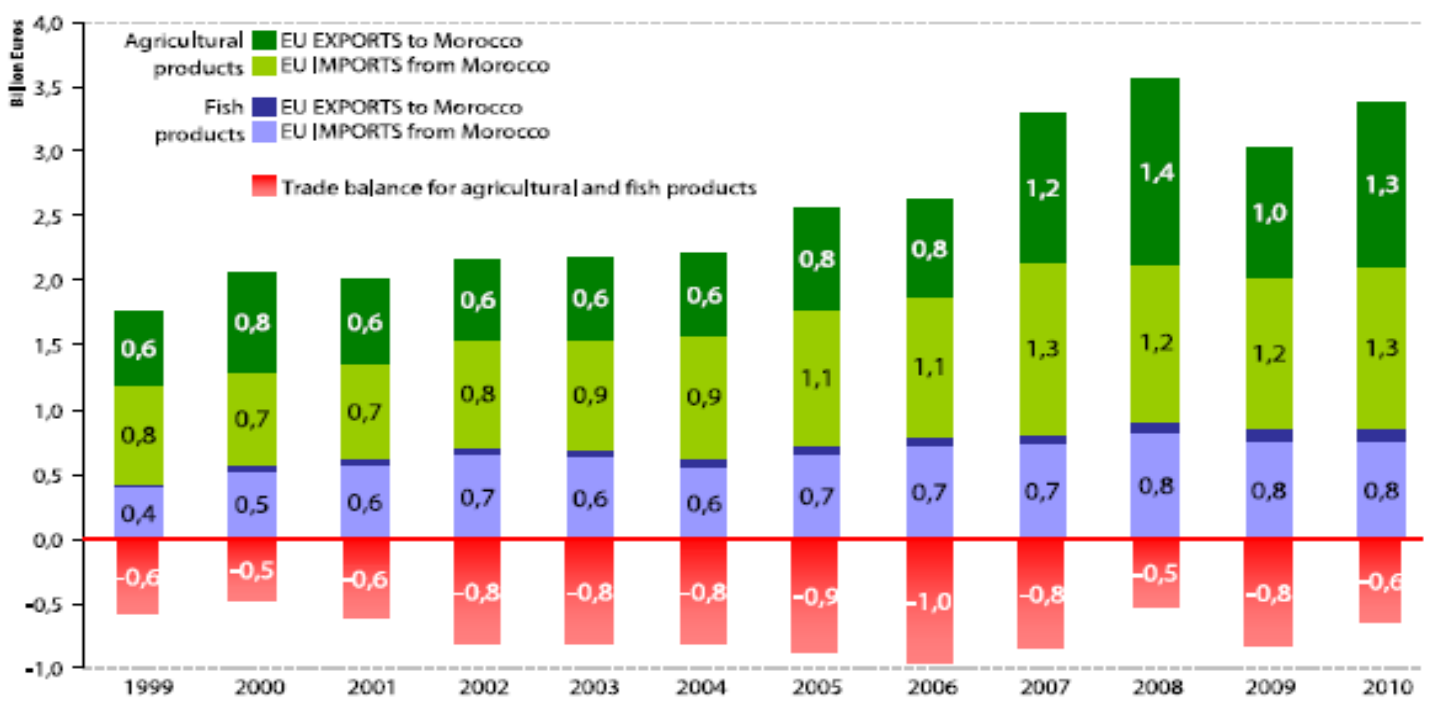

Gráfico 3. Comercio europeo de productos de agricultura y pesca con Marruecos( $€ \mathrm{Gm})$

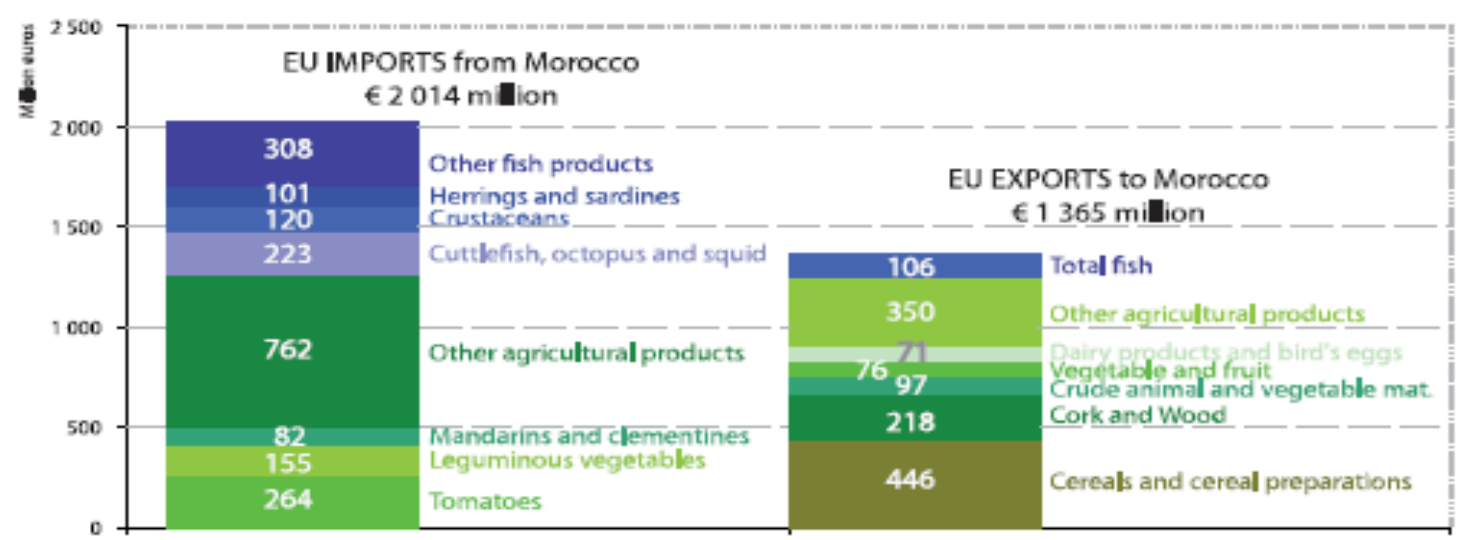

Fuente: EU-Moroccan Agreement on Agricultural and Fishery Products

\footnotetext{
${ }^{27}$ Ver: "Resolución del Parlamento Europeo sobre el Acuerdo UE-Marruecos sobre medidas recíprocas de liberalización del comercio de productos agrícolas y productos de la pesca", Parlamento Europeo, 16 de febrero de 2012, en

http://www.europarl.europa.eu/sides/getDoc.do?pubRef=-//EP//TEXT+TA+P7-TA-2012$0055+0+\mathrm{DOC}+\mathrm{XML}+\mathrm{V} 0 / / \mathrm{ES}$

${ }^{28} \mathrm{Ibid}$.
} 
Si bien la agricultura y la pesca constituyen un polo de internacionalización para Marruecos, el proceso de liberalización no es ni ascendente ni completo. En su proceso de desarrollo agrícola, el Estado combina apertura y proteccionismo. Para determinados productos (como el cereal) mantiene un sistema de tarifas cambiante y negocia los precios de entrada con sus socios comerciales ${ }^{29}$. Se asegura así la protección a los productores nacionales -que ven disminuida la competencia al alcanzar en algunos casos las tasas de importación el 100\% del precio original- y a los consumidores locales -que se beneficiar, además de un sistema de subsidios que controla el precio del cereal- ${ }^{30}$.

Tabla 3. Principales productos exportados (en millares de dirhams. 1 dirham $=11$ euros)

\begin{tabular}{|c|c|c|c|}
\hline & 2008 & 2009 & 2010 \\
\hline Exportaciones agrícolas & 15,2 & 13,9 & 15,8 \\
\hline Cítricos & 3,2 & 2,5 & 2,8 \\
\hline Verduras frescas, congeladas o en salmuera & 2 & 2,2 & 1,9 \\
\hline Tomates frescos & 2 & 2,4 & 1,7 \\
\hline Frutas frescas, congeladas o en salmuera & 1,7 & 1,6 & 1,5 \\
\hline Conservas de verduras & 1,5 & 1,3 & 1,5 \\
\hline
\end{tabular}

Fuente: “Agriculture marocaine en chiffres. 2010", Ministère de l'Agriculture et de la Pêche

4.1.3. El nuevo acuerdo de comercio Unión Europea - Marruecos, ¿satisfactorio para Marruecos?

Marruecos mantiene una relación privilegiada con la UE. Es el receptor de la mayor cantidad de fondos, con un presupuesto de 580 millones de euros para el periodo $(2011-2013)^{31}$. El país magrebí fue el primero en obtener el 'estatuto avanzado' en el marco de la Política Europea de Vecindad (PEV). Lo hizo en 2008 y refleja sus esfuerzos de fortalecimiento y transformación institucional para profundizar su integración regional con la $\mathrm{UE}^{32}$.

En febrero de 2012 se firma un nuevo acuerdo de libre mercado entre Marruecos y la UE que afecta el comercio de productos de agricultura, pesca y ganadería. Dicho acuerdo permitirá que, a lo largo de la próxima década y de forma pautada, el $70 \%$ de las exportaciones agro-alimentarias de la UE entren en Marruecos libres de aranceles. Los productos liberalizados (o en proceso de liberalización) incluyen aceites y vegetales, a excepción del trigo, para el que Marruecos impondrá tasas de entrada más altas. Como

\footnotetext{
${ }^{29}$ Lemerle, Caroline: EU policy coherence: the Common Agricultural Policy and Development A case study about Morocco, en http://lib.ugent.be/fulltxt/RUG01/001/789/888/RUG01-001789888_2012_0001_AC.pdf.

${ }^{30}$ Ibid.

${ }^{31}$ Ver europolitics, 2013

${ }^{32}$ Lemerle, op.cit.
} 
contrapartida, la UE retirará de forma inminente los aranceles de entrada al $55 \%$ de las importaciones de Marruecos. Algunas salvaguardas, sin embargo, permanecen. El acuerdo permitirá sólo incrementos moderados de las cuotas para ciertos productos sensibles, como los tomates, las fresas, los pepinos y el ajo, e incluye cuotas de temporada para evitar una oferta excesiva en los mercados europeos. ${ }^{33}$

Desde el punto de vista económico, el nuevo acuerdo supone un paso más hacia la liberalización, perseguida por el gobierno marroquí durante las dos últimas décadas puesto que el libre comercio se ha ligado a los planes de desarrollo del país (también desde las instituciones europeas). A pesar de que Marruecos ha firmado tratados comerciales con otros Estados, con la Unión Europea mantiene una relación prioritaria y diferenciada. No sólo es su principal socio comercial, sino que, además, los acuerdos incorporan contrapartidas financieras o medidas de acompañamiento para la transformación de las empresas marroquíes. ${ }^{34}$ Entre las cinco prioridades que establece el Plan UE-Marruecos, se encuentra la modernización de la economía y el apoyo al Plan Maroc Vert ${ }^{35}$. En este marco ha de entenderse el programa de la UE que refuerza el pilar II de la reforma institucional y legislativa del sector agro-alimentario con 70 millones de euros ${ }^{36}$ La contrapartida, sin embargo, respecto al Acuerdo de Libre Comercio (ACL) con Estados Unidos, es que con la UE el acuerdo no es comprehensivo y ha de ser negociado e implementado por etapas y sectores, con el agravante de que grupos de productos sensibles se postergan o se reservan para discusiones posteriores. ${ }^{37}$

\section{Mapa 1. Las regiones de Marruecos}

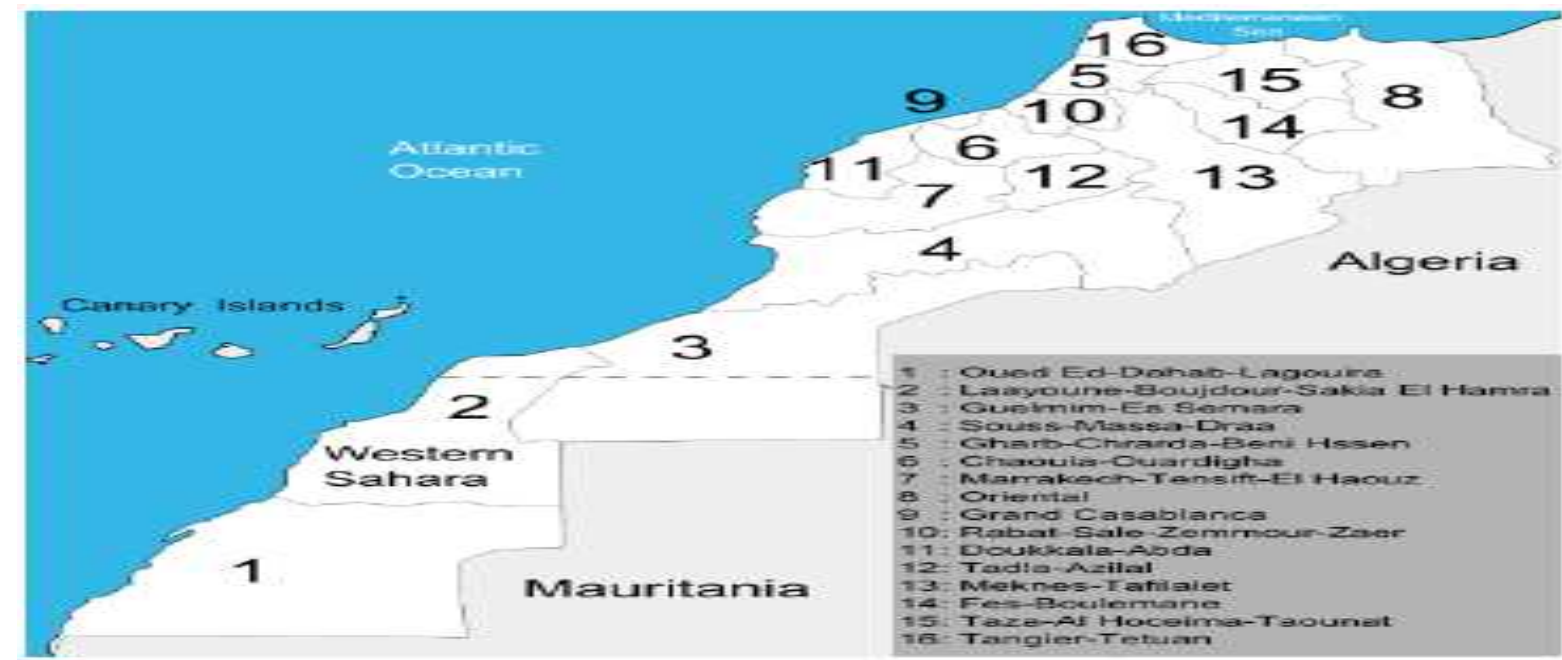

Fuente: Commission Consultative de la Régionalisation du royaume du Maroc

\footnotetext{
33“"EU parliament approves Morocco agriculture trade deal", Ahram online, 17 de febrero de 2012.

${ }^{34}$ Fernández Molina, Irene: "El Acuerdo de Libre Comercio entre Marruecos y Estados Unidos y os actores internos no gubernamentales de la política exterior marroquí: el caso de CGEM", Revista Internacional de Estudios Mediterráneo (REIM), nº7 (Enero-Mayo 2009).

${ }^{35}$ Las otras cuatro prioridades son (1) el sector social, (2) el refuerzo institucional, (3), los Derechos del Hombre y gobernanza, y (4) medio ambiente. Ver Comisión Europea: "Document de travail: mise en ouvre de la politique européenne de voisinage en 2010, rapport pays: Maroc", 25 de mayo de 2011, en http://ec.europa.eu/world/enp/pdf/progress2011/sec 11_651_fr.pdf.

${ }^{36}$ Comisión Europea: "Document de travail: mise en ouvre de la politique européenne de voisinage en 2010 , rapport pays: Maroc", 25 de mayo de 2011, en http://ec.europa.eu/world/enp/pdf/progress2011/sec 11_651_fr.pdf.

${ }^{37}$ FAO (2000): "Agriculture, Trade and Food Security Issues and Options in the WTO negotiations from the perspective of developing countries", en http://www.fao.org/docrep/003/X8731e/x8731e00.htm\#TopOfPage.
} 
Desde el punto de vista político, el acuerdo permite (a) la diferenciación respecto a sus vecinos, al alcanzar mayores cuotas de liberalización en el mercado europeo y (b) la aceptación de facto de la soberanía marroquí sobre el Sáhara Occidental y sobre sus recursos económicos. Desde que se propusiera como país candidato en 1987, Marruecos ha mostrado su deseo de una mayor integración y reconocimiento europeo. La UE reconoce incluso su progresiva adopción de la normativa sanitaria y fito-sanitaria comunitaria. ${ }^{38}$ Además Marruecos consigue que su punto de vista 'territorial' se imponga en un tratado de validez internacional. La inclusión del Sáhara Occidental -cuyo dossier es una de las líneas rojas en el ámbito doméstico y una de las altas prioridades de la política exterior- es capital. El Ministro marroquí de agricultura y pesca, Aziz Akhannouch, se declara "satisfecho con que el acuerdo no imponga restricciones que afectan nuestra unidad territorial" 39 . La inclusión de lo que las autoridades marroquíes denominan 'provincias del sur' ha causado protestas por parte de varios ONGs. Western Sahara Resource Watch señala que se aumentará la importancia de las industrias de tomates que se encuentran en suelo disputado, y que de ello se beneficiaran no las poblaciones locales (tienen ventajas sociales y económicas los marroquíes y aquellos saharauis que se reclaman marroquíes que los que reclaman la independencia), sino las empresas de propiedad estatal y las de titularidad francesa ${ }^{40}$.

\subsection{La perspectiva tunecina}

Tras la Primavera Árabe, Túnez se encuentra en un proceso de reconstrucción política y económica. Trabajamos, sin embargo, con la hipótesis de la continuación de las dinámicas del sector agrícola, de la relación con la Unión y del intercambio de productos agro-alimentarios.

Con una economía diversa y orientada hacia el comercio, la agricultura permanece como uno de los principales motores económicos del país: contribuye con un $10 \%$ al $\mathrm{PIB}^{41}$ y emplea al $16 \%$ de la población activa ${ }^{42}$.

Desde el inicio del Proceso de Barcelona (1992) y con su entrada en la Organización Mundial del Comercio (1995), el país se encuentra inmerso en un proceso de liberalización comercial. El sector agrícola no ha escapado a esta transformación que busca una mayor inserción en la economía regional y mundial. Con variaciones anuales, las tasas de protección nominal -la relación porcentual entre el precio interno y el precio en el mercado mundialtiende a disminuir ${ }^{43}$. Se sigue protegiendo, sin embargo, la llamada "petit agriculture" o la

\footnotetext{
${ }^{38}$ Comisión Europea (2011): Mise en oeuvre de la politique européenne de voisinage en 2010 Rapport pays: Maroc en http://www.enpi-info.eu/library/sites/default/files/sec 11 651_fr.pdf.

39 "EU parliament approves Morocco agriculture trade deal", FAO, 17 de febrero de 2012, en http://neareast.fao.org/Pages/NewsDetails.aspx?lang=EN\&I=0\&DId=0\&CId=0\&CMSId=21\&id=2403241. ${ }^{40}$ Ibid.

${ }^{41}$ CIA (2012): World Factbook: Tunisia, en https://www.cia.gov/library/publications/the-world-factbook/geos/ts.html (según estimaciones de 2010) La industria representa el 34,6\% y los servicios el 54,8\% del PIB.

${ }^{42}$ Observatoire National de l'Agriculture: Agrégats Économiques, en http://www.onagri.tn/index.php?option=com content\&task=view\&id=232\&Itemid=152.

${ }^{43}$ Banco Africano de Desarrollo (2012): "Distorsions aux incitations et politique agricole en Tunisie : une première analyse", en http://www.afdb.org/fileadmin/uploads/afdb/Documents/Publications/Brochure\%20Note\%20politique\%20fran\% C3\%A7ais.pdf.
} 
producción agrícola nacional, los ingresos de los pequeños y grandes agricultores y el empleo en las zonas rurales ${ }^{44}$.

Tabla 5. Tasa de protección nominal y efectiva

\begin{tabular}{|c|c|c|c|c|c|c|c|c|}
\hline & \multicolumn{2}{|c|}{ 1990-1994 } & \multicolumn{2}{|c|}{ 1995-1999 } & \multicolumn{2}{|c|}{$2000-204$} & \multicolumn{2}{|c|}{ 2005-2009 } \\
\hline & TPN & TPE & TPN & TPE & TPN & TPE & TPN & TPE \\
\hline Cereales & 1,36 & 1,67 & 1,21 & 1,4 & 1,13 & 1,27 & 1,87 & 1,91 \\
\hline Trigo duro & 1,43 & 1,74 & 1,17 & 1,3 & 1,14 & 1,27 & 1,87 & 1,91 \\
\hline Trigo blando & 1,76 & 2,53 & 1,41 & 1,74 & 1,33 & 1,6 & 1,02 & 1,11 \\
\hline Cebada & 1,19 & 1,46 & 1,39 & 1,86 & 1,01 & 1,08 & 0,82 & 0,84 \\
\hline Arboricultura & 0,84 & 0,61 & 0,76 & 0,55 & 0,77 & 0,53 & 0,77 & 0,54 \\
\hline Cítricos & 1,35 & 1,53 & 1,46 & 1,66 & 1,18 & 1,34 & 0,91 & 1,03 \\
\hline Aceite oliva & 0,85 & 0,46 & 0,61 & 0,32 & 0,77 & 0,41 & 0,76 & 0,41 \\
\hline Dátiles & 0,66 & 0,44 & 0,68 & 0,46 & 0,63 & 0,42 & 0,77 & 0,53 \\
\hline Ganadería & 1,46 & 1,01 & 0,7 & 0,75 & 0,74 & 0,8 & 0,57 & 0,59 \\
\hline Bovino & 0,92 & 1,01 & 0,7 & 0,75 & 0,74 & 0,8 & 0,57 & 0,59 \\
\hline Ovino & 0,53 & 0,56 & 0,74 & 0,81 & 0,78 & - & - & - \\
\hline Leche & 2,3 & 2,47 & 1,82 & 1,8 & 1,6 & 1,54 & 1,31 & 1,22 \\
\hline
\end{tabular}

Fuente: Distorsions aux incitations et politique agricole en Tunisie : une première analyse

Desde 2007, Túnez implementa el "XI Plan de Desarrollo", que se presenta como una estrategia global y comprehensiva de mejora del sector agrícola con el fin de adaptarse a las transformaciones nacionales e internacionales ${ }^{45}$. Se articula en torno a dos prioridades:

- Plano internacional. Liberalización del comercio de productos agro-alimentarios (bien de forma bilateral con la UE, bien de manera multilateral en el marco de la

\footnotetext{
${ }^{44}$ Las tres dimensiones son prioridades del XI Plan de Desarrollo. Ver: "Xième Plan de Developpement (20072011). Rapport de la Commission Sectorielle du Developpement Agricole, de la Peche et des Ressources Naturelles", Ministère de l'Agriculture et des Ressources Hydrauliques, Republique Tunisienne, en http://www.onagri.tn/PLANS\%20DE\%20DEVELOPPEMENT/XIPLAN/XIPLAN_Fr.pdf. 
Organización Mundial del Comercio).

- Plano nacional. Mejor aprovechamiento de los recursos naturales (especialmente los hidráulicos ${ }^{46}$ ) y consolidación de la seguridad alimentaria del país, "vector de soberanía nacional [y] elección estratégica constante" ${ }^{47}$. Con la inclusión de la protección del medio ambiente, incorpora en la planificación de su desarrollo agrícola nacional uno de los ejes prioritarios de la UE: la lucha contra el cambio climático.

Como en el caso marroquí, se ha desarrollado una agricultura dual, que combina las explotaciones pequeñas, en manos de numerosos propietarios con aquellas orientadas a la exportación y a la integración en la economía global. Lo que hace que se haya mantenido un alto nivel de proteccionismo (en la frontera, mediante las cuotas de aduana, y en el mercado doméstico, mediante el sistema de subvenciones).

La seguridad alimentaria, entendida como "un equilibrio de la balanza comercial de productos agroalimentarios" 48 , está entre las primeras preocupaciones del gobierno tunecino. La subida global de los productos de primera necesidad a partir de 2007 y una producción agrícola baja y volátil, nada estable y dependiente de la climatología, ha aumentado la percepción de "riesgo alimentario".

\section{Gráfico 4. Productividad de la agricultura vs. productividad de la industria}

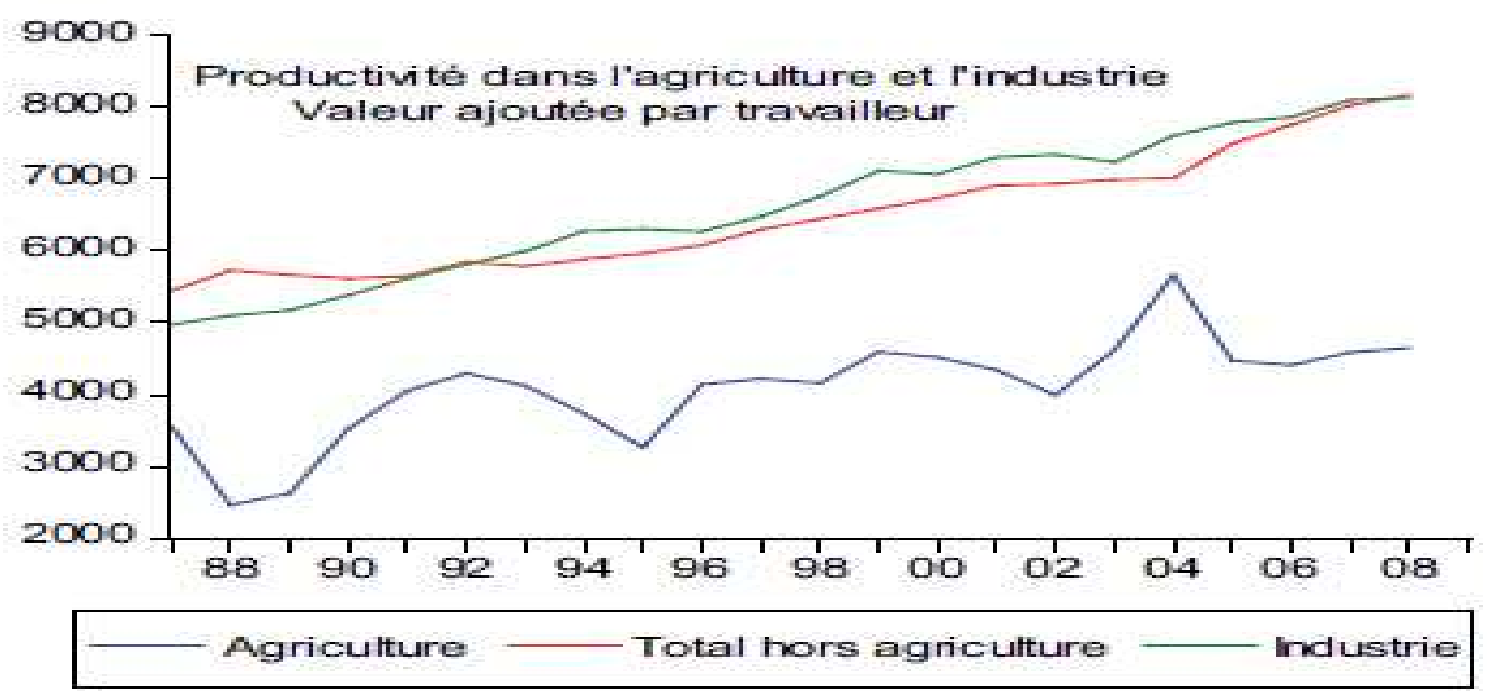

Fuente: Distorsions aux incitations et politique agricole en Tunisie : une première analyse

\footnotetext{
${ }^{46}$ Las autoridades nacionales tunecinas están especialmente preocupadas por el agua, su aprovechamiento sostenible y su distribución entre los diferentes sectores económicos (agricultura, industria, urbanismo...). En este sentido, durante los últimos años se están llevando a cabo una serie de reformas que pretender (a) garantizar la 'seguridad hídrica', muy relacionada con la seguridad alimentaria -en tanto forma parte de la misma y es necesaria para asegurar la producción agrícola- y (b) proteger los recursos hídricos nacionales. Para obtener más información sobre el Proyecto de Reforma del Código del Agua y sus decretos de aplicación, ver: "Système Euro-Méditerranéen de l'Information sur le savoire-faire dans le Domain de l'Eau (SEMIDE)", en http://www.semide.tn/.

${ }^{47}$ Ibid.

${ }^{48}$ Bachta, Mohamed Salah (2011): L'Agriculture tunisienne : Performances et Menaces de non Durabilité, Institut Arabe des Chefs d'Entreprises, en http://www.ctee.tn/documents/Etude\%20agriculture\%20juin\%202011.pdf.
} 
El interés de los poderes públicos pasa por que el sector satisfaga las necesidades alimentarias de una población en crecimiento y contribuya a la estabilización de la balanza comercial de productos agro-alimentarios. Podemos hablar de una política de desarrollo y regulación de los mercados agrícolas ${ }^{49}$ que ha conseguido que "las tasas de cobertura de las necesidades nacionales por la producción interior sean cerca del $48 \%$ para los cereales (...), 100\% para la ganadería y $88 \%$ para las aceites."

Tabla 4. Evolución de la balanza comercial de productos agro-alimentarios

$$
\begin{gathered}
\text { Importaciones (millones } \\
\text { de dinares) }
\end{gathered} \quad \begin{gathered}
\text { Exportaciones } \\
\text { (millones de dinares) }
\end{gathered}
$$

Saldo

Tasa de cobertura

$(\%)$

Año

\section{0}

2001

2002

2003

2004

2005

2006

2007

2008

2009

2010

Fuente: L'Agriculture tunisienne : Performances et Menaces de non Durabilité
628,2

$-154,2$

80,29

887,6

669,9

$-217,7$

75,47

1143

556,5

$-586,5$

48,69

894,1

565,8

$-328,3$

63,28

1037,3

1227,2

189,9

118,31

1093,3

1225,6

132,3

112,1

1321,9

1599

277,1

120,96

2042,8

1615,5

$-427,3$

79,08

2600,9

1849,9

$-751$

71,13

1593,2

1631,2

38

102,39

1339,65

1156,88

$-182,77$

87,17

${ }^{49}$ Ibid.
${ }^{50}$ Ibid. 
Para cumplir el doble objetivo de (a) garantizar la seguridad alimentaria y (b) preparar el campo para el proceso de liberalización en curso y la búsqueda de mercados en el exterior, las autoridades nacionales han desarrollado una política de vectores múltiples ${ }^{51}$ :

- Aumento de la productividad y de la competitividad.

- Estabilización de la producción (aprovechamiento de la climatología favorable y sostenimiento de la producción durante las épocas de sequía).

- Énfasis sobre el proceso de transformación (con el fin de absorber la producción agrícola fresca y contribuir al equilibrio entre la oferta y la demanda para evitar las variaciones de precios).

- Medidas de acompañamiento en cuanto a organización del sector público que permita ampliar los servicios prestados, modernización del sector y profesionalización de la mano de obra.

- Promoción del acceso del capital privado y de la inversión extranjera.

Junto a las medidas de carácter autárquico, se pretende que la agricultura contribuya significativamente al crecimiento económico nacional. De ahí que el segundo eje de desarrollo agrícola sea la dinamización de la exportación y la atracción de inversión privada extrajera; el aprovechamiento de las oportunidades nacidas a la luz de los acuerdos con la UE.

\subsubsection{El comercio con la UE en materia de alimentos}

La Unión Europea, con la que realiza el $62 \%$ de sus intercambios comerciales ${ }^{52}$, es el primer socio comercial para Túnez. La tendencia se mantiene de forma clara respecto al comercio de productos agro-alimentarios. Aunque algunos bienes tienen ya como destino el Golfo, como Qatar o Arabia Saudi ${ }^{53}$, el mercado europeo es el receptor del $80 \%$ de las exportaciones y el origen del $75 \%$ de los productos agrícolas tunecinos. A Europa llegan especialmente el aceite de oliva $(39 \%)$, la pesa $(17 \%)$ y los dátiles $(13 \%)^{54 ;}$ son los denominados "productos de exportación tradicional" ${ }^{\text {. }}$. La pauta de la especialización se mantiene.

Hasta el año 2000, Túnez era importador neto de productos agrícolas ${ }^{56}$, a partir de entonces sigue una pauta de crecimiento en sus exportaciones globales y en las de productos agrícolas. Éstos representan el $11 \%$ de los bienes que se destinan al exterior ${ }^{57}$.

\footnotetext{
51"Xième Plan de Developpement ...", op.cit.

${ }^{52}$ World Trade Centre: Tunisia, en http://www.wto.org/english/thewto_e/countries_e/tunisia_e.htm

53،Vers l'ouverture du secteur agricole en Tunisie", Oxford Business Group, en http://www.oxfordbusinessgroup.com/economic_updates/tunisie-vers-louverture-du-secteur-agricole.

${ }^{54}$ Banco Africano de Desarrollo, op.cit.

55، "Xième Plan de Developpement ...", op.cit.

56 Banco Africano de Desarrollo (2012): Distorsions aux incitations et politique agricole en Tunisie : une première analyse, en http://www.afdb.org/fileadmin/uploads/afdb/Documents/Publications/Brochure\%20Note\%20politique\%20fran\% C3\%A7ais.pdf.

${ }^{57}$ Observatoire National de l'Agriculture: "Agrégats Économiques", en http://www.onagri.tn/index.php?option=com content\&task=view\&id=232\&Itemid=152.
} 
Tabla 5. Comercio exterior total y agrícola

\begin{tabular}{|c|c|c|c|c|c|c|}
\hline & \multicolumn{2}{|c|}{$\begin{array}{l}\text { Todos los productos } \\
\text { (millares de dinares) }\end{array}$} & \multicolumn{2}{|c|}{$\begin{array}{l}\text { Productos agrícolas } \\
\text { (millares de dinares) }\end{array}$} & \multicolumn{2}{|c|}{$\begin{array}{l}\text { Parte de productos agrícolas } \\
\text { (en \%) }\end{array}$} \\
\hline & Import. & Export. & Import. & Export. & Import. & Export. \\
\hline 2000 & 11737957 & 8004702 & 1407402,7 & 1157739,2 & 11,99 & 14,46 \\
\hline 2001 & 13697300 & 9503700 & 1640793,9 & 1279325,5 & 11,98 & 13,46 \\
\hline 2002 & 13510879 & 9748618 & 178366,1 & 1171084,1 & 13,01 & 12,01 \\
\hline 2003 & 14038900 & 10343600 & 1517941,3 & 1250510,1 & 10,81 & 12,09 \\
\hline 2004 & 15960300 & 12054900 & 1844908,4 & 1990661,1 & 11,56 & 16,51 \\
\hline 2005 & 17101326 & 13607701 & 1908048,8 & 2059565 & 11,16 & 15,14 \\
\hline 2006 & 19750203 & 15316323 & 2174171,1 & 2566957 & 11,01 & 16,76 \\
\hline 2007 & 24279800 & 19234899 & 3004850,6 & 2813768,5 & 12,38 & 14,63 \\
\hline 2008 & 30231215 & 23637070 & 3872157,8 & 4104451,1 & 12,8 & 17,36 \\
\hline 2009 & 25877631 & 19469202 & 2803005 & 2788243,2 & 10,83 & 14,32 \\
\hline
\end{tabular}

Fuente: L'Agriculture tunisienne : Performances et Menaces de non Durabilité

De acuerdo a la lógica europea, la liberalización del comercio entre Túnez y la Unión Europea sigue una pauta de implementación progresiva y sectorial. El Acuerdo de Asociación TúnezUE, firmado en 1995 y que entra en vigor en 1998, constituye el marco para conseguir "de manera progresiva una liberalización mayor de los intercambios recíprocos de productos agrícolas y de la pesca" ${ }^{, 5}$ y remite a futuros encuentros para fijar las medidas de liberalización.

En el año 2000, Túnez se convierte en el primer socio mediterráneo en negociar un Acuerdo Agrícola. Entra en vigor en 2001 y establece la eliminación y reducción de los derechos de aduana y la ampliación de las cuotas o contingentes arancelarios preferenciales ${ }^{59}$. A partir de 2006 se establece una "hoja de ruta" para la liberalización de los productos

\footnotetext{
58 “Accord Euro-Méditerranéen établissant une association entre la Communauté européenne et ses États membres, d'une part, et la République tunisienne, d'autre part", Journal Officiel des Communautés Européennes, 30 de marzo de 1998, en http://eur-lex.europa.eu/LexUriServ/LexUriServ.do?uri=OJ:L:1998:097:0002:0174:FR:PDF.

${ }^{59}$ Ver: "Decisión del Consejo relativa a la celebración del Acuerdo en forma de Canje de Notas entre la Comunidad Europea y la República de Túnez sobre las medidas de liberalización recíprocas y la modificación de los Protocolos agrícolas del Acuerdo de asociación CE-República de Túnez", 22 de diciembre de 2000, en http://www.boe.es/doue/2000/336/L00092-00109.pdf.
} 
agrícolas, que comprende también los productos de pesca. Estos últimos pueden exportarse a la UE sin derechos de aduana y sin restricciones temporales ni cuantitativas.

Los cambios políticos de la Primavera Árabe han conducido a una reformulación de las relaciones euro-mediterráneas en las que el acceso al mercado común europeo cobra un renovado significado. El comercio de bienes agro-alimentarios (y el de servicios) ha sido el gran beneficiado.

Tras un año de negociaciones, en noviembre de 2012 el Consejo de Asociación EUTúnez aprueba el "estatuto avanzado" del país magrebí. Responde así a una repetida demanda de Túnez, que lo solicita en el año 2008 -en el marco de la Asociación UE-Túnez- y de nuevo en marzo de 2010, mediante la presentación de un documento sobre las propuestas relativas al "estatuto avanzado" ${ }^{60}$. Para las autoridades tunecinas supone una triple victoria:

A Le permite avanzar en la integración política y económica con la Unión y conseguir así una mayor cuota de mercado para un sector estratégico como el agrícola. Una de las prioridades del nuevo marco de relación es la liberalización del comercio de productos agro-alimentarios siguiendo, eso sí, la pauta del desmantelamiento aduanero y tarifario asimétrico y paulatino ${ }^{61}$. Túnez se convierte en uno de los cuatro Países Terceros Mediterráneos (PTM) con los que la UE negocia un Acuerdo de Libre Comercio Profundo y Completo.

A Recibirá 400 millones de euros para el periodo 2011-2013 en materia de cooperación siguiendo la lógica de "Trade for Aid"62. El nuevo Programa Indicativo Nacional (PIN) para este periodo establece como uno de sus objetivo prioritarios "el apoyo al desarrollo y a la competitividad de las empresas, en el sector agrícola (...) para prepararlas para la presión competitiva y para las oportunidades ofrecidas por el acuerdo de libre comercio con la UE y las negociaciones en curso para ampliarlo.",63

A Adquiere un estatuto similar al del vecino marroquí, de manera que podrá competir en términos similares en la carrera por el mercado común europeo. Salvando, eso sí, las diferencias en área dedicada a la agricultura y en volumen de producción, que inclinan la balanza hacia Marruecos.

\subsection{La perspectiva argelina}

\subsubsection{Los hidrocarburos sobre el sector agrícola}

Argelia se distancia de sus vecinos en cuanto a estructura del PIB -y peso del sector agrícola en el mismo- y en cuanto a objetivos de política exterior vinculados a los productos agroalimentarios y al acceso al mercado único europeo. La menos liberada de las economías del

\footnotetext{
60 "Túnez", Comisión Europea, en http://ec.europa.eu/europeaid/where/neighbourhood/country-cooperation/tunisia/tunisia_fr.htm. 61 UE-Túnez: "Déclaration conjointe "Vers un partenariat privilégié", 2 de febrero de 2012, en http://europa.eu/rapid/press-release_MEMO-12-62_en.htm.

${ }^{62}$ Ibid.

63 "Tunisie: Programme Indicatif National (2011-2013)", en http://eeas.europa.eu/delegations/tunisia/documents/page content/pin_tunisie 2011_2013 fr.pdf; los otros tres son (a) apoyo al empleo y a la reforma del mercado de trabajo para facilitar la integración de los jóvenes; (b) apoyo a las reformas económicas para profundizar la integración en la economía mundial y en el mercado comunitario, para aumentar la competitividad de la economía tunecina y para facilitar los intercambios de bienes, servicios e inversiones; y (c) apoyo al sector de la justicia.
} 
Magreb central y el sistema político más cerrado, encuentra en los hidrocarburos su fuente principal de riqueza. Éstos representan aproximadamente el $60 \%$ de los ingresos del país, el $30 \%$ del PIB y el $95 \%$ de las exportaciones. ${ }^{64}$ El carácter rentista ${ }^{65}$ del Estado argelino determina en buen medida su política doméstica y sus relaciones exteriores (políticas y comerciales). No hay, sin embargo, que minusvalorar la importancia del sector agrícola, que si bien es "estructuralmente importador" ${ }^{66}$, emplea al $23 \%$ de la población activa, es decir, a aproximadamente 1,6 millones de personas ${ }^{67}$.

El relativo escaso desarrollo del sector agro-alimentario en Argelia está relacionado con unas condiciones climatológicas y naturales adversas y con un modelo económico basado en los hidrocarburos. Mañé y Bustos señalan que este poco peso de la agricultura en la estructura estatal argelina tiene que ver también con el tipo de colonización sufrida por el país que, a diferencia de Túnez o Marruecos "impidió la formación de cualquier forma autóctona de cohesión social o cultural, a la vez que destruyó los recursos de poder de las élites precoloniales (agricultura y comercio)." 68

Argelia, a la que varios informes sitúan en riesgo de "inseguridad alimentaria"69, es uno de los grandes importadores mundiales de productos agro-alimentarios. El país magrebí importó, según datos de 2007, el 4\% de los cereales vendidos en el mundo durante ese año. El 70\% de los casi 24 millones de quintales de trigo que consume anualmente son de procedencia exterior. ${ }^{70}$ Argelia se encuentra, por tanto, en una situación de dependencia de los niveles de producción agrícola internacional y de los precios de los mismos en el mercado global. Conscientes de la vulnerabilidad que genera esta situación, las autoridades gubernamentales argelinas persiguen el aumento de la producción local de cereales y han aumentado para ello las ayudas públicas al Plan Nacional de Desarrollo de la Agricultura

\footnotetext{
${ }^{64}$ CIA, op.cit.

65 "Podemos definir un Estado rentista, como aquel que genera economías petrolero-rentistas o dicho de otro modo, cuya gestión del sector de los hidrocarburos se lleva a cabo con el objetivo — político- de lograr el máximo posible de renta del subsuelo para los residentes nacionales. En estas economías se cumplen todas estas condiciones: Primero, la economía es fundamentalmente una exportadora de crudo o recursos naturales sin elaborar. En segundo lugar, los ingresos obtenidos con estas exportaciones son considerados el principal instrumento de intervención pública y esto se traduce en unas políticas de gasto destinadas fundamentalmente a la legitimación del sistema vigente. En tercer lugar, se crea o consolida una economía no productiva, caracterizada por el importante peso del sector de los hidrocarburos, que financia a un también significativo sector servicios, que se nutre o de bienes de consumo importados o de «petrocapitales». Por último, como consecuencia - y no como causa - de todo ello: la evolución de los principales agregados macroeconómicos es función de la evolución de los precios del petróleo en el mercado internacional”, en Bustos, Rafael y Mañé, Aurelia (2009): "Argelia: estructura poscolonial de poder y reproducción de élites sin renovación”, en Izquierdo, Ferrán (de.): "Poder y regímenes en el mundo árabe contemporáneo", Barcelona, CIDOB.

"66"La filière agroalimentaire en Algérie", Ubifrance en Algerie, en

http://www.financesmediterranee.com/images/stories/Fichiers-FCM/Missions_FCM/ME_-

filire agroalimentaire.pdf.

${ }^{67}$ Ibid.

${ }_{68}^{6}$ Bustos y Mañé, op.cit.

69 “Tous les paramètres qui font la crise alimentaire d'aujourd'hui étaient en train de se mettre en place il y a dix ans, la montée des biocarburants, celle de la consommation alimentaire dans les pays émergeants, la demande algérienne en produits laitiers compte tenu de la jeunesse de sa population, les besoins en semences pour développer les productions de base. L'Algérie n'a rien voulu voir venir. Aujourd'hui, elle est réduite à courir après les prix internationaux pour subventionner la consommation intérieure au moment où des pays comme la Chine, l'Inde ou le Vietnam sont exportateurs nets de riz », explique Farid Cherbal, spécialiste en biologie moléculaire, citado por Ihsane, El Kadi: "L'Algérie, gros importateur de blé, a raté sa récolte 2008", Les Afriques, en

http://www.lesafriques.com/produits-de-base/l-algerie-gros-importateur-de-ble-a-rate-sarecolte.html? Itemid=308.

${ }^{70}$ Ibid.
} 
$(\text { PNDA })^{71}$. Desde el Estado se ha lanzado la "Política de renovación agrícola y rural", que pretende aumentar los niveles de productividad del campo, disminuir la dependencia exterior y dinamizar el empleo. Esta política se basa en una mejor interacción entre las filiares de producción y las de transformación, que están ya en el estadio industrial. ${ }^{72}$

\subsubsection{Las relaciones comerciales con la Unión Europea}

La denominada "factura alimentaria" supone aproximadamente el $20 \%$ de las importaciones argelinas ${ }^{73}$. Tres factores paralelos han contribuido a que esta partida haya aumentado a lo largo del último año:

- Efecto precio. El precio internacional de los principales productos agrícolas aumentó una fuerte subida a lo largo de 2011; una subida especialmente significativa en el caso del trigo, que cuesta hoy un $38 \%$ más.

- Efecto compra. Las autoridades argelinas han elevado su capacidad de almacenamiento comprando hasta un $45 \%$ más de productos agrícolas en el mercado internacional; pretenden así disminuir el riesgo de penuria alimentaria y aumentar el colchón de protección frente a posibles revueltas populares en el marco de la Primavera Árabe.

- Efecto demanda. Las medidas que a lo largo de 2011 han pretendido elevar el nivel adquisitivo de los consumidores argelinos ha creado una mayor demanda de productos agrícolas importados.

Tabla 6. Evolución de las importaciones argelinas (desde Francia)

Productos

Importaciones 2011

(en millones de USD)
Evolución

2012/2010(\%)
$\%$ total de las importaciones argelinas 2011
Cereales

Vehículos de turismo

Productos farmacéuticos

Vehículos de transporte

Leche y productos lácteos

Azúcar

Otros
4025

2109

1955

1783

1525

1162

31150
(+) $103 \%$

(+) $45 \%$

(+) $17 \%$

(+) $15 \%$

(+) $54 \%$

(+) $71 \%$

(+) $2,6 \%$

\section{$8,70 \%$}

$4,50 \%$

$4,20 \%$

$3,80 \%$

$3,30 \%$

$2,50 \%$

$67,00 \%$

Fuente: Le commerce extérieur de l'Algérie en 2011, Embajada de Francia en Argelia

\footnotetext{
${ }^{71}$ Ibid.

${ }^{72}$ "La filière agroalimentaire...", op.cit.

73 "Le commerce extérieur de l'Algérie en 2011", Ambassade de France en Algerie, en http://www.ambafrancedz.org/IMG/pdf/Le_commerce exterieur_de 1_Algerie.pdf.
} 
Europa es el primer socio comercial de Argelia, que absorbe, ella sola, el $25 \%$ de las exportaciones de productos alimentarios de la Unión hacia la zona mediterránea ${ }^{74}$.

\section{Gráfico 5. Comercio exterior de Argelia}

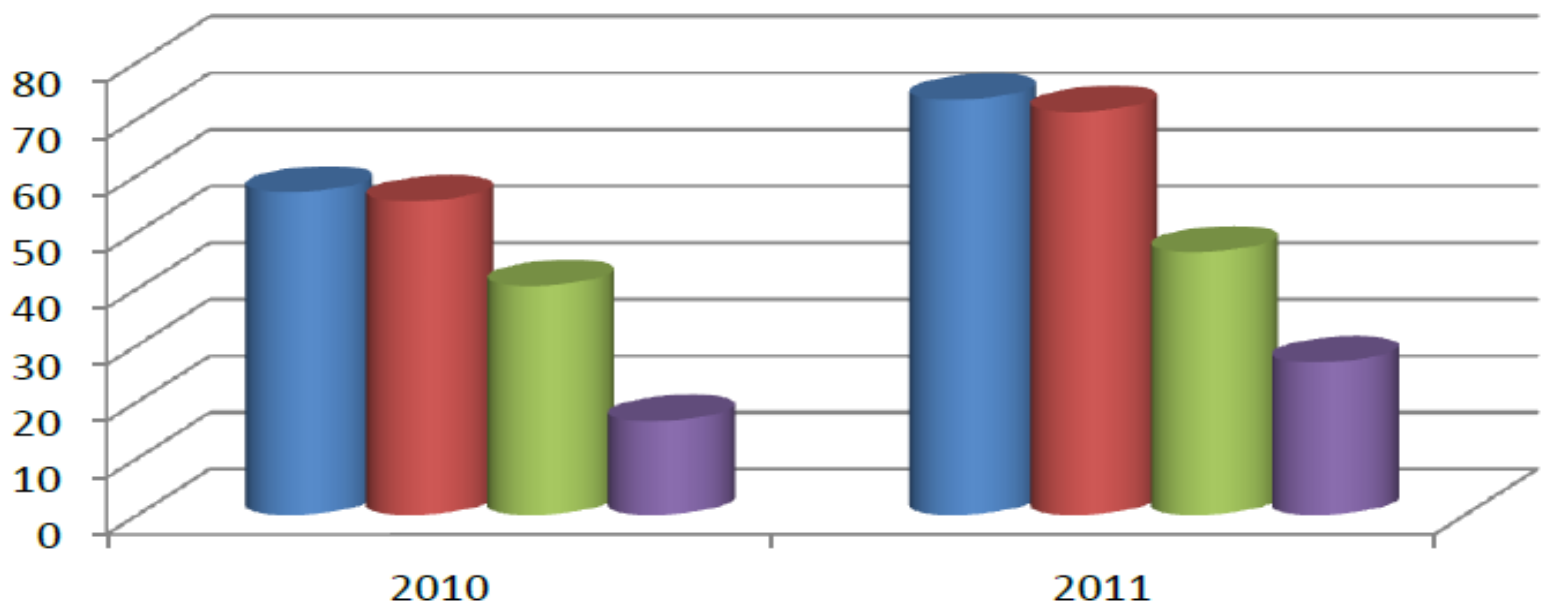

Leyenda: Azul-exportaciones; rojo-porcentaje de hidrocarburos; verde-importaciones; violeta-saldo.

Fuente: Le commerce extérieur de l'Algérie en 2011, Embajada de Francia en Argelia

Entre las dos entidades se establecen unas fructíferas relaciones bilaterales capitalizadas en buena medida por los hidrocarburos, que arrojan, en la balanza comercial, un saldo positivo a favor de Argelia. No en vano, es el tercer exportador mundial de gas y su principal mercado es el europeo ${ }^{75}$ (Ver tabla 8 sobre los principales clientes argelinos).

\footnotetext{
${ }^{74}$ Ver: CIHEAM- IEMed (2012): Mediterra 2012: Diète méditerranéenne pour un développement régional durable, Paris, SciencesPo Les Presses et CIHEAM en http://www.ciheam.org/index.php/en/publications/mediterra-2012.

75"Algérie: activités économiques", Larousse, en http://www.larousse.fr/encyclopedie/divers/activit\%C3\%A9s \%C3\%A9conomiques de_1Alg\%C3\%A9rie/1856 $\underline{16}$.
} 
Tabla 7. Los diez principales clientes argelinos

$\begin{array}{lccc}\text { Principales clientes } & \text { Valor } & \text { Porcentaje } & \text { Evolución } \\ & \text { millones de USD } & \% & \text { agosto 2011/2012 } \\ \text { USA } & 836 & 15,21 & -18,36 \\ \text { Italia } & 678 & 12,33 & -24,16 \\ \text { España } & 516 & 9,39 & -17,57 \\ \text { Francia } & 436 & 7,93 & 8,46 \\ \text { Gran Bretaña } & 397 & 7,22 & 83,8 \\ \text { Canadá } & 369 & 6,71 & 204,96 \\ \text { Países Bajos } & 316 & 5,75 & 64,58 \\ \text { Brasil } & 302 & 5,49 & -39,84 \\ \text { China } & 207 & 377 & - \\ \text { Turquía } & 206 & 3,75 & -\end{array}$

Fuente: Estadísticas del Comercio Exterior de Argelia, República Argelina Democrática y Popular

Los países de la UE se mantienen como los principales suministradores del mercado nacional argelino. Los intercambios comerciales aumentaron en 2011 un 24,2\% respecto al año anterior. Las exportaciones Argelia-UE crecieron en un 30\% (de 28 Mds USD a 36,3 Mds USD); lo que supone el $49 \%$ sobre el cómputo exportador total. Las importaciones desde la Unión conocieron también un aumento del 17\% (de 20,7 Mds USD a 24,2 Mds USD), lo que supone más de la mitad de las importaciones totales de Argelia. 
Tabla 8. Los diez principales suministradores argelinos

\begin{tabular}{|c|c|c|c|c|}
\hline & $\begin{array}{c}\text { Importaciones } \\
\text { millones de USD }\end{array}$ & $\begin{array}{c}\text { Evolución } \\
\text { 2011/2010 (\%) }\end{array}$ & $\begin{array}{l}\text { Porcentaje del } \\
\text { mercado }\end{array}$ & $\begin{array}{c}\text { Evolución de la } \\
\text { parte del mercado } \\
2011 / 2010\end{array}$ \\
\hline Francia & 7026 & (+) 15,18 & 15,12 & (+) $0,05 \mathrm{pt}$ \\
\hline Italia & 4611 & (+) 13,80 & 9,93 & (+) $0,25 \mathrm{pt}$ \\
\hline China & 4581 & (+) 3,15 & 9,86 & $-1,11 \mathrm{pt}$ \\
\hline España & 3320 & (+) 25,90 & 7,15 & (+) $0,62 \mathrm{pt}$ \\
\hline Alemania & 2508 & (+) 7,13 & 5,4 & $-0,43 \mathrm{pt}$ \\
\hline Estados Unidos & 2137 & (+) 2,30 & 4,6 & $-0,74 \mathrm{pt}$ \\
\hline Argentina & 1783 & (+) 46,63 & 3,84 & (+) $0,84 \mathrm{pt}$ \\
\hline Brasil & 1759 & (+) 95,01 & 3,79 & (+) $1,55 \mathrm{pt}$ \\
\hline Corea del Sur & 1608 & $-18,58$ & 3,46 & $-1,39 \mathrm{pt}$ \\
\hline Turquía & 1370 & $-9,57$ & 2,95 & $-0,82 \mathrm{pt}$ \\
\hline
\end{tabular}

Fuente: Le commerce extérieur de l'Algérie en 2011, Embajada de Francia en Argelia

El Acuerdo de Asociación entre Argelia y al UE fue firmado en 2002 y entra en vigor en septiembre de 2005. Uno de los aspectos positivos que incorpora, destacado desde le Ministerio de Comercio argelino, es que no se limita a cuestiones económicas o comerciales, sino que "prevé también disposiciones para la protección de la industria nacional a través de medidas antidumping, medidas compensatorias, medidas de salvaguarda y medidas excepcionales a favor de las industrias de nueva creación y ciertos sectores en proceso de reestructuración." "76 Sin embargo, los resultados obtenidos están "alejados de las expectativas de Argelia" "77. A pesar de que el mercado europeo es el destino de más del $52 \%$ de sus productos, el volumen de exportaciones es muy bajo si se excluyen los hidrocarburos. A los ojos de las autoridades argelinas, no se cumple, por tanto, uno de los objetivos prioritarios de la puesta en marcha del Acuerdo. A saber, "aumentar una diversificación de la economía nacional para permitir el desarrollo de las exportaciones excluyendo los hidrocarburos"78.

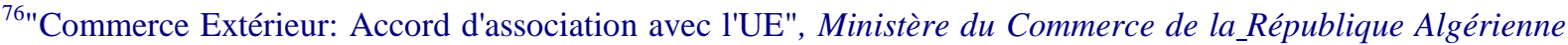
Démocratique et Populaire, en http://www.mincommerce.gov.dz/?mincom=sommaireEU1.

${ }^{77}$ Ibid.

${ }^{78}$ Ibid.
} 
Tabla 9. Evolución del comercio con la UE (importaciones y exportaciones)

\begin{tabular}{|c|c|c|c|c|c|c|}
\hline & \multicolumn{2}{|c|}{2009} & \multicolumn{2}{|c|}{2010} & \multicolumn{2}{|c|}{2011} \\
\hline & Valor & $\%$ & Valor & $\%$ & Valor & $\%$ \\
\hline Importaciones de la UE & 20645 & 53 & 20406 & 51 & 24112 & 52 \\
\hline \multirow[t]{3}{*}{ Importaciones Globales } & 39103 & 100 & 40212 & 100 & 46453 & 100 \\
\hline & \multicolumn{2}{|c|}{2009} & \multicolumn{2}{|c|}{2010} & \multicolumn{2}{|c|}{2011} \\
\hline & Valor & $\%$ & Valor & $\%$ & Valor & $\%$ \\
\hline Export. hidrocarburos a UE & 617 & 58,93 & 1064 & 65,7 & 1645 & 76,4 \\
\hline Export. hidrocarburos globales & 1047 & 100 & 1619 & 100 & 2152 & 100 \\
\hline Exportaciones totales -UE & 23334 & 53,4 & 20009 & 35,1 & 36295 & 49,5 \\
\hline Exportaciones totales globales & 43689 & 100 & 57053 & 100 & 73390 & 100 \\
\hline
\end{tabular}

Nota: Valor expresado en millones de dólares

Fuente: Estadísticas del Comercio Exterior de Argelia, República Argelina Democrática y Popular

Argelia se siente pues damnificada en cierto modo por los resultados del Acuerdo de Asociación con la UE y ha emprendido el camino contrario al de sus vecinos. En vez de por una mayor apertura, aboga ahora por una ralentización del proceso de liberalización comercial que le permita reconstruir su tejido industrial y favorecer el desarrollo del sector agroalimentario. En palabras del ministro de comercio argelino:

"Este ritmo de desmantelamiento (tres etapas) ha tenido como consecuencia consolidar la parte de la UE en el mercado argelino sin desembocar en una verdadera política de partenariado que es uno de los objetivos establecidos por este Acuerdo [de Asociación]. De esta manera, este desmantelamiento se ha convertido así en un contratiempo real a la aplicación de ciertas política de desarrollo de la empresa argelina.(...) Es por tanto imperativo que el Estado reaccione para revisar el ritmo y el nivel de desmantelamiento para las ramas industriales en dificultad así como el reajuste de las concesiones tarifarias agrícolas de acuerdo con la política agrícola de renovación rural (...) para las filiares agrícolas que necesitan una protección adapta de tal manera que el ritmo y el nivel de desmantelación no constituya un contratiempo a su desarrollo",79

\footnotetext{
79" Allocution de Monsieur le Ministre du Commerce. Journée de sensibilisation et d'information sur le nouveau schéma de démantèlement tarifaire avec l'Union Européenne", Ministère du Commerce de la République Algérienne Démocratique et Populaire, en
} 
El 15 de junio de 2010, tras la 55 a sesión del Consejo de Asociación en Luxemburgo, Argelia introduce una demanda formal para la revisión de las concesiones tarifarias de los productos agrícolas y agro-alimentarios (y del desmantelamiento tarifario para los productos industriales). Pretende que se retrase el calendario inicial para la implementación del Área de Libre Cambio hasta 2020 en lugar de 2017 y recaudar los derechos de aduana en virtud de las disposiciones del Acuerdo de Asociación para una lista de productos sensibles ${ }^{80}$. El objetivo no es otro que "restituir o paralizar las tasas de derecho de aduana para los productos de filiares sensible a fin de permitir a nuestras empresas públicas y privadas tener la oportunidad de alcanzar el nivel en la perspectiva de una preparación para una competencia leal" ${ }^{\text {81 }}$ Este giro proteccionista está en sintonía con la política de renovación agrícola y rural que pretende incentivar la producción alimentaria local.

El nuevo calendario de desmantelamiento tarifario prevé:

- Un retrase de tres años en la puesta en práctica de la zona de libre comercio y el restablecimiento o congelación de las tasas de derecho de aduana de más de mil líneas tarifarias que cubren un gran número de filiales y grupos industriales.

- Una tasa de protección superior para determinados productos sensibles.

- Un nivel de protección suplementaria para la producción nacional argelina lo que “ da un margen de preferencia a nuestras industrias y constituye un instrumento integrado en las políticas de desarrollo industrial con el objetivo de convertir nuestras empresas en competitivas ante la UE" 82

\section{Conclusiones}

La primera hipótesis que se confirma es la de la diferenciación. Argelia se desmarca de sus vecinos por el peso sobredimensionado del sector de los hidrocarburos en su estructura económica y en sus relaciones exteriores.

Podemos, sin embargo, extraer conclusiones comunes para los casos de Marruecos y Túnez. El agrícola es un sector estratégico en sus respectivos equilibrios económicos y políticos y en el entramado relacional europeo. La UE constituye para ambos un vector de integración en la economía mundial -en términos de exportaciones y de atracción de

http://www.mincommerce.gov.dz/seminaire/semn280812/allocuminfr.pdf.

80"Commerce Extérieur: Accord d'association avec l'UE", Ministère du Commerce de la_République Algérienne Démocratique et Populaire, en http://www.mincommerce.gov.dz/?mincom=sommaireEU1. El artículo 11 estipula que Argelia puede revisar el calendario del desmantelamiento tarifario para un número de productos que no sobrepase el $15 \%$ de las importaciones originarias de la UE y que el derecho de aduana restablecido no exceda el $25 \%$. En lo que concierne a los productos agrícolas y agro-alimentarios, el artículo 16 prevé un reajuste de las concesiones tarifarias agrícolas en caso de cambio de la política agrícola

${ }^{81}$ "Allocution de Monsieur le Ministre du Commerce. Journée de sensibilisation et d'information sur le nouveau schéma de démantèlement tarifaire avec l'Union Européenne", Ministère du Commerce de la République Algérienne Démocratique et Populaire, en http://www.mincommerce.gov.dz/seminaire/semn280812/allocuminfr.pdf.

${ }_{82 "}$ Allocution de Monsieur le Ministre du Commerce. Journée de sensibilisation et d'information sur le nouveau schéma de démantèlement tarifaire avec l'Union Européenne", Ministère du Commerce de la République Algérienne Démocratique et Populaire, en http://www.mincommerce.gov.dz/seminaire/semn280812/allocuminfr.pdf. 
inversiones- y un elemento transformador en sus planes de desarrollo nacionales. Entre los denominados Países Terceros Mediterráneos (PTM) y la UE se establece una relación dialéctica constante de manera que los intereses de ambas partes (nivel doméstico) se reflejan en los acuerdos firmados (nivel internacional). Este movimiento se produce también en el sentido inverso: la negociación de los acuerdos UE-PTM (nivel internacional) tienen un impacto relevante sobre los programas nacionales de los PTM (nivel doméstico). De ahí:

A La incorporación de la dimensión medio-ambiental y la protección de los recursos naturales en los planes de desarrollo agrícola tanto de Marruecos (Plan Maroc Vert) como de Túnez (XI Plan de Développement).

A La asunción del rol pautado desde el ámbito internacional en términos de especialización (de un determinado bien agrícola) y de temporalidad (límites en los contingentes de importación según la época del año y tendencia a adaptar el calendario de producción nacional).

La Primavera Árabe ha supuesto una ventana de oportunidad para que los PTM puedan negociar acuerdos de libre comercio más beneficiosos y ampliar cuotas de mercado para los productos agro-alimentarios. El interés europeo de garantizar la estabilidad del área euromediterránea y la decisión de emplear instrumentos de cooperación económica y comercial para ello ha facilitado a los actores magrebíes la transposición de sus agendas al ámbito internacional. Aunque en un estadio diferente, Marruecos y Argelia se benefician de la negociación de un Acuerdo de Libre Comercio Profundo y Comprehensivo (ALCPC) que ha supuesto un nuevo nivel en la liberalización del comercio de productos agro-alimentarios para el primero y que se prevé tenga un resultado similar en el caso del segundo.

La liberalización en materia agro-alimentaria (comercio e inversión) no ha de entenderse, sin embargo, como un proceso lineal y ascendente con tendencia a la apertura completa del mercado. El sector agrícola, por lo capital de su contribución económica a las arcas del Estado y por su particular relación con la estabilidad social y política del mismo, conserva cierto carácter de "domaine reservé". Conviven en este campo una liberalización progresiva -impulsada desde el exterior y que encuentra un eco profundo en las élites beneficiaras de los réditos de la apertura- y un proteccionismo persistente -en forma de subvenciones al consumo y/o a la producción-. Un proteccionismo que si bien habla en tierras tunecinas y marroquíes, eleva aún más la voz en el desierto argelino. 